\title{
Factors associated with mental health consultation in South Korea
}

\author{
Jieun Jang ${ }^{1,2}$, Sang Ah Lee ${ }^{1,2}$, Woorim Kim ${ }^{1,2}$, Young Choi ${ }^{1,2}$ and Eun-Cheol Park ${ }^{2,3^{*}}$
}

\begin{abstract}
Background: The aim of this study was to examine factors associated with the use of mental health consultation for depressive symptoms.

Methods: We used data from the 2013 Community Health Survey, which included responses from 13,269 individuals who reported that they had experienced depressive symptoms for more than 2 weeks in Korea. We investigated associations between mental health consultation rates for depressive symptoms and sociodemographic, socioeconomic, and health-related factors. Logistic regression analysis was used to examine the significance of associations.

Results: Among participants who report depressive symptoms, 16.0\% ( $n=2120)$ undergo mental health consultation. Respondents with a college education or over are more likely to undergo mental health consultation (odds ratio $(O R)=1.49 ; 95 \% \mathrm{Cl}: 1.21-1.84)$ than respondents with less education. Individuals aged 70 years or above are less likely to receive mental health consultation than those aged between 19 and 29 years. Females exhibit higher mental health consultation rates than males. Respondents who are divorced show greater odds of receiving mental health consultation than respondents who are married and cohabitate with their spouse.

Conclusions: This study indicates that rates of use of mental health consultation services are lower among older adults and men and higher among divorced people. Educational level shows a significant positive association with mental health consultation among Koreans. The results could have implications for mental health policy in many ways in Korea.
\end{abstract}

Keywords: Depression, Mental health consultation, Education, Depress, Mental health

\section{Background}

Questions about why individuals do not seek mental health services for treatment of their mental illness and how to improve use of mental health consultation services are important topics worldwide [1, 2]. Depression is a common disease, affecting at least 300 million people around world [3]. However, people with depression often still do not receive mental health consultation for depression [4]. People with depression are less likely to obtain continuous treatment for depression due to lack of information on how to manage depression and the stigma associated with the

\footnotetext{
* Correspondence: ECPARK@yuhs.ac

${ }^{2}$ Institute of Health Services Research, Yonsei University, Seoul, Republic of Korea

${ }^{3}$ Department of Preventive Medicine \& Institute of Health Services Research, Yonsei University College of Medicine, 50 Yonsei-ro, Seodaemun-gu, Seoul 120-752, Republic of Korea

Full list of author information is available at the end of the article
}

condition [5-7]. The World Health Organization projected for the year 2030 that depression would be a major cause of the disease burden [8]. Depression is a significant public health problem [9].

Depression is an important issue, because it is a major cause of suicide [10]. Mounting evidence suggests that depressive disorder is strongly associated with completed suicide [11, 12]. About $60 \%$ of all suicides are estimated to stem from depression and other mood disorders [1316]. Organisation for Economic Co-operation and Development (OECD) statistics indicate that, in 2013 and 2014, Korea ranked first in suicide rates among OECD countries [17]. Therefore, addressing depression is an important issue for Korea.

Mental health consultation is an effective treatment for depressive symptoms, but many do not seek the help of mental health services [18-20]. The results of the 
2013 Community Health Survey (CHS) indicate that approximately $5.8 \%$ of Koreans are affected by depressive symptoms, but only $16 \%$ of those depressed receive mental health consultation for their depression symptoms. Mental health consultation for treatment of depression is as important as the use of medications [18]. Despite the fact that mental health consultation is an effective treatment for depression, it is a real problem that people with depressive symptoms do not receive a mental health consultation.

Utilization of mental health services has been found to be related to several factors $[18,19]$. Howard et al. noted that mental health services were associated with educational level, marital status, and race [21]. Vessey, John T et al. reported that the most educated people are the most likely to utilize mental health services [22]. Moreover, divorced people are the most likely to consult with mental health services than married, bereaved, and unmarried people [22]. They identified that there was no strong relationship between the utilization of mental health services and income level [22]. In addition, stigma is a barrier to the use of mental health consultation. Stigma has been shown to influence help seeking and consistency with treatment for mental illness [23]. People with suicidal thoughts also may have more severe depressive symptoms than people with no suicidal thoughts. Severe mental disorder is significantly related to the use of mental health services [24]. Demyttenaere $\mathrm{K}$. et al. indicated that people with serious mental disorders show much higher use of mental health treatment than people with moderate mental disorders [24].

Seeking help for mental health problems has been shown to be related with several factors. These include age, gender, and educational level [4, 21]. Educational level, in particular, exhibits several associations with the use of mental health consultation. A higher educational level appears to dispose an individual to greater access to health information [25, 26]. Moreover, individuals who have attained higher educational levels are more likely to actively respond to the information they receive $[25,26]$. Meanwhile, negative attitudes towards mental health services and distrust of the effect of treatment also affect the utilization of mental health consultation services [27]. Therefore, education may be essential in improving help-seeking attitudes and willingness to undergo mental health consultation.

The purpose of this study was to identify several factors related to the use of mental health consultation. In Korea, the government supports mental health promotion centers in each city [28]. Since 2005, a mental care health hotline (+82-129) has provided mental health consultations from mental health experts anywhere and anytime [29]. Additionally, the government has proposed policies to address depression rates and recommend mental health consultation for depressive symptoms in Korea. Therefore, it is essential to study factors associated with the use of mental health consultation.

\section{Methods \\ Study population}

Data from the nationwide 2013 Community Health Survey (CHS) were used for this study. The CHS used a cross-sectional study design and was performed in cooperation with the Korea Centers for Disease Control and Prevention and municipalities in Korea. The Korea Centers for Disease Control and Prevention approved the use of data from CHS through the CHS website (https://chs.cdc.go.kr/chs/index.do). A total of 228,781 individuals responded to the survey. Our study population consisted only of those who had depressive symptoms. We selected participants using the question 'Within the last year, did you experience any emotions, such as sadness or despair, continuously for more than 2 weeks, which increased difficulties in daily life?' Respondents who answered 'no' $(n=215,345)$ and didn't answer the question $(n=59)$ were excluded from our study population. Respondents who answered 'yes' were classified as individuals with depressive symptoms $(n=$ 13,377). We excluded individuals with data missing for use of mental health consultation services $(n=1)$, marital status $(n=11)$, educational level $(n=26)$, occupation $(n=11)$, stress level $(n=16)$, smoking status $(n=3)$, suicidal thoughts $(n=11)$, perceived health status $(n=2)$, and physical activity $(n=27)$. Therefore, a final sample population of 13,269 people was included for analysis in this study.

\section{Variables}

The dependent variable was participants' use of mental health consultation services. Participants who had depressive symptoms $(n=13,269)$ were asked the question, 'Did you receive any mental health consultation (e.g., medical institution, professional consulting institution, local health centre) for these symptoms?' We examined the participants' use of mental health consultation services based on a 'yes' or 'no' answer.

The main independent variable of interest in this study was education level of the participants. We examined education attainment using a survey question. The question asked for the respondents to indicate the last school grade that was completed. In order to compare the educational level from a global perspective, the International Standard Classification of Education (ISCED) was used in the analysis. International Standard Classification is one of the standard frameworks to compare education statistics. Low educational level included ISCED classification of $0-1$ (early childhood education and primary education) and medium educational level included 
ISCED classification of 2 (lower secondary education). High education was defined as ISCED classification of 3 (upper secondary education), and college or over as ISCED classification of 5 to 8 (short-cycle tertiary education, bachelor or equivalent, master or equivalent, doctoral or equivalent.

Other variables in the analysis included sociodemographic, socioeconomic, health-behaviour, and healthcondition variables. The sociodemographic factors were age (19 to 29 years, 30 to 39 years, 40 to 49 years, 50 to 59 years, 60 to 69 years, 70 or above) and gender (male, female). The socioeconomic factors were marital status (married and cohabit, married and non-cohabit, bereaved, divorced, unmarried), region (capital, urban, rural), household income level (divided into quartiles), and occupation (managers, professionals, clerical support workers, service workers, sales worker, skilled agricultural, forestry and fishery workers, craft and related trades workers, plant and machine operators, and assemblers, elementary occupations, armed forces occupations, others).

The capital region included Seoul, which is the capital of Korea, and Gyeonggi province, which surrounds Seoul. About a population of 20 million (about $50 \%$ of Korea) live in the capital region. Urban areas included metropolitan cities usually with a population of about 1 million. Rural areas included the remaining geographic areas, excluding capital and urban regions. The standards of dividing house income level per year were less than $8,400,000$ won (about 75,350,000 USD), less than 24,000,000 won (about 215,290,000 USD), less than 40,000,000 won (about $358,800,000$ USD), and more than $40,000,000$ or above (about 358,800,000 USD). Occupation was classified by the Korean Standard Classification of Occupations (KSCO). The KSCO is based on the International Standard Classification of Occupations. The International Standard Classification of Occupations is one of the standard frameworks for classifying jobs according to the tasks and duties undertaken in the job [30]. This classification was simplified as high-skilled white collar, low-skilled white collar, high-skilled blue collar, low-skilled blue collar, and others. The high-skilled white collar group included managers, professionals, and clerical support workers. Low-skilled white collar workers included service workers and sales workers. The high-skilled blue collar group included skilled agricultural, forestry, and fishery workers, as well as craft and related trade workers. Lowskilled blue collar workers included plant and machine operators and assemblers and elementary occupations. Others included armed forces occupations, students, and other job statuses.

Health-behaviour factors included physical activity (inactive and active by metabolic equivalent task), smoking status (never or former, current [within a year]) and alcohol consumption (never or former, current [within a year]). Health-condition factors included stress level (very, little no), suicidal thoughts (yes or no), sleep duration ( $<7 \mathrm{~h}, 7$ to $8 \mathrm{~h}, \geq 9 \mathrm{~h})$, and perceived health status (good, normal, bad). Participants were asked the question, 'Did you have suicidal thoughts within the last year?' And we examined the participants' suicidal thoughts based on a 'yes' or 'no' answer.

\section{Statistical analysis}

Statistical analysis was performed using SAS software, version 9.4 (SAS Institute, Cary, NC, USA). All analyses included the use of weighted variables. Chi-square tests were used to confirm the significant differences between respondents who did and did not obtain mental health consultation for depression symptoms. Logistic regression analysis was used to determine odds ratios (ORs) and 95\% confidence intervals (CIs). Subgroup analysis was performed according to age and suicidal thoughts. A $p$-value $<0.05$ was considered to indicate a statistically significant result.

\section{Results}

Table 1 presents the general characteristics of the study populations. There are 4019 males (30.3\%) and $9250 \mathrm{fe}-$ males (69.7\%) included in this study. Of the 13,269 participants who have depressive symptoms, 2120 (16.0\%) received mental health consultation and 11,149 (84.0\%) did not. The rate of use of mental health consultation is the lowest among participants with low educational level (14.6\%) relative to among college or over (15.5\%). Of the 13,269 participants, the rate of receiving mental health consultation is the lowest among the 70 years or above participants (12.4\%). The rate of use of mental health consultation is the highest among divorced people (21.8\%). Moreover, females (17.3\%) show higher mental health consultation rates than males (13.0\%).

Table 2 presents the results for the factors associated with the use of mental health consultation services for depressive symptoms. Educational level shows a significant positive association with the use of mental health consultation. Respondents in the college or over level are more likely to receive mental health consultation for depressive symptoms $(\mathrm{OR}=1.49 ; 95 \% \mathrm{CI}: 1.21-1.84)$, compared to respondents in the low educational level. Individuals in the 70 years or above age group are less likely to receive mental health consultation $(\mathrm{OR}=0.46$; 95\% CI: $0.33-0.64$ ) than the 19 to 29 years old groups. Females shows higher mental health consultation rates $(\mathrm{OR}=1.19 ; 95 \% \mathrm{CI}: 1.02-1.38)$ than males. There is no significant association between household income level and utilization of mental health consultation. Respondents who are divorced have greater odds of receiving mental health consultation $(\mathrm{OR}=1.32$; $95 \% \mathrm{CI}$ : $1.08-$ 
Table 1 General characteristics of the study population

\begin{tabular}{|c|c|c|c|c|c|c|c|}
\hline \multirow[t]{3}{*}{ Variables } & \multicolumn{2}{|l|}{ Total } & \multicolumn{3}{|c|}{ Mental health consultation } & & \multirow[t]{3}{*}{$P$-value* } \\
\hline & \multirow[b]{2}{*}{$\mathrm{N}$} & \multirow[b]{2}{*}{$\%$} & \multicolumn{2}{|l|}{ YES } & \multicolumn{2}{|l|}{ NO } & \\
\hline & & & $\mathrm{N}$ & $\%$ & $\mathrm{~N}$ & $\%$ & \\
\hline Total & 13,269 & 100.0 & 2120 & 16.0 & 11,149 & 84.0 & \\
\hline Educational level - ISCED & & & & & & & 0.0005 \\
\hline Low & 4832 & 36.4 & 704 & 14.6 & 4128 & 85.4 & \\
\hline Medium & 1606 & 12.1 & 295 & 18.4 & 1311 & 81.6 & \\
\hline High & 4119 & 31.0 & 700 & 17.0 & 3419 & 83.0 & \\
\hline College or over & 2712 & 20.4 & 421 & 15.5 & 2291 & 84.5 & \\
\hline Age & & & & & & & $<.0001$ \\
\hline $19-29$ & 1305 & 9.8 & 210 & 16.1 & 1095 & 83.9 & \\
\hline $30-39$ & 1745 & 13.2 & 292 & 16.7 & 1453 & 83.3 & \\
\hline $40-49$ & 2144 & 16.2 & 365 & 17.0 & 1779 & 83.0 & \\
\hline $50-59$ & 2695 & 20.3 & 453 & 16.8 & 2242 & 83.2 & \\
\hline $60-69$ & 2259 & 17.0 & 412 & 18.2 & 1847 & 81.8 & \\
\hline $70 \leq$ & 3121 & 23.5 & 388 & 12.4 & 2733 & 87.6 & \\
\hline Gender & & & & & & & $<.0001$ \\
\hline Male & 4019 & 30.3 & 523 & 13.0 & 3496 & 87.0 & \\
\hline Female & 9250 & 69.7 & 1597 & 17.3 & 7653 & 82.7 & \\
\hline Household income level & & & & & & & 0.0129 \\
\hline Quartile 1 (lowest) & 3518 & 26.5 & 536 & 15.2 & 2982 & 84.8 & \\
\hline Quartile 2 & 3349 & 25.2 & 595 & 17.8 & 2754 & 82.2 & \\
\hline Quartile 3 & 3048 & 23.0 & 468 & 15.4 & 2580 & 84.6 & \\
\hline Quartile 4 (highest) & 3354 & 25.3 & 521 & 15.5 & 2833 & 84.5 & \\
\hline Region & & & & & & & 0.7874 \\
\hline Capital (Seoul, Gyeonggi) & 4366 & 32.9 & 705 & 16.1 & 3661 & 83.9 & \\
\hline Urban & 2604 & 19.6 & 423 & 16.2 & 2181 & 83.8 & \\
\hline Rural area & 6299 & 47.5 & 992 & 15.7 & 5307 & 84.3 & \\
\hline Marital status & & & & & & & $<.0001$ \\
\hline Married-cohabit & 7638 & 57.6 & 1178 & 15.4 & 6460 & 84.6 & \\
\hline Married-no cohabit & 449 & 3.4 & 72 & 16.0 & 377 & 84.0 & \\
\hline Bereaved & 2440 & 18.4 & 364 & 14.9 & 2076 & 85.1 & \\
\hline Divorced & 908 & 6.8 & 198 & 21.8 & 710 & 78.2 & \\
\hline Unmarried & 1834 & 13.8 & 308 & 16.8 & 1526 & 83.2 & \\
\hline Occupation & & & & & & & $<.0001$ \\
\hline High-skilled white collar & 1756 & 13.2 & 215 & 12.2 & 1541 & 87.8 & \\
\hline Low-skilled white collar & 1499 & 11.3 & 234 & 15.6 & 1265 & 84.4 & \\
\hline High-skilled blue collar & 1528 & 11.5 & 194 & 12.7 & 1334 & 87.3 & \\
\hline Low-skilled blue collar & 1469 & 11.1 & 193 & 13.1 & 1276 & 86.9 & \\
\hline Others & 7017 & 52.9 & 1284 & 18.3 & 5733 & 81.7 & \\
\hline Physical activity & & & & & & & 0.0265 \\
\hline Inactive & 8932 & 67.3 & 1471 & 16.5 & 7461 & 83.5 & \\
\hline Active & 4337 & 32.7 & 649 & 15.0 & 3688 & 85.0 & \\
\hline Smoking status & & & & & & & 0.3816 \\
\hline Never or former & 10,807 & 81.4 & 1741 & 16.1 & 9066 & 83.9 & \\
\hline
\end{tabular}


Table 1 General characteristics of the study population (Continued)

\begin{tabular}{|c|c|c|c|c|c|c|c|}
\hline \multirow[t]{3}{*}{ Variables } & \multicolumn{2}{|l|}{ Total } & \multicolumn{3}{|c|}{ Mental health consultation } & \multirow[b]{3}{*}{$\%$} & \multirow[t]{3}{*}{$P$-value* } \\
\hline & \multirow[b]{2}{*}{ N } & \multirow[b]{2}{*}{$\%$} & \multicolumn{2}{|l|}{ YES } & \multirow{2}{*}{$\frac{\mathrm{NO}}{\mathrm{N}}$} & & \\
\hline & & & N & $\%$ & & & \\
\hline Current & 2462 & 18.6 & 379 & 15.4 & 2083 & 84.6 & \\
\hline Alcohol consumption & & & & & & & 0.0023 \\
\hline Never or former & 5289 & 39.9 & 908 & 17.2 & 4381 & 82.8 & \\
\hline Current (within a year) & 7980 & 60.1 & 1212 & 15.2 & 6768 & 84.8 & \\
\hline Stress level & & & & & & & $<.0001$ \\
\hline Very & 8441 & 63.6 & 1590 & 18.8 & 6851 & 81.2 & \\
\hline Little & 4114 & 31.0 & 451 & 11.0 & 3663 & 89.0 & \\
\hline No & 714 & 5.4 & 79 & 11.1 & 635 & 88.9 & \\
\hline Suicidal Thought & & & & & & & $<.0001$ \\
\hline Yes & 7295 & 55.0 & 1472 & 20.2 & 5823 & 79.8 & \\
\hline No & 5974 & 45.0 & 648 & 10.8 & 5326 & 89.2 & \\
\hline Sleeping duration & & & & & & & 0.1173 \\
\hline Less than $7 \mathrm{~h}$ & 7400 & 55.8 & 1193 & 16.1 & 6207 & 83.9 & \\
\hline $7-8 \mathrm{~h}$ & 5162 & 38.9 & 797 & 15.4 & 4365 & 84.6 & \\
\hline 9 h or over & 707 & 5.3 & 130 & 18.4 & 577 & 81.6 & \\
\hline Perceived health status & & & & & & & $<.0001$ \\
\hline Good & 2488 & 18.8 & 262 & 10.5 & 2226 & 89.5 & \\
\hline Normal & 4810 & 36.2 & 687 & 14.3 & 4123 & 85.7 & \\
\hline Bad & 5971 & 45.0 & 1171 & 19.6 & 4800 & 80.4 & \\
\hline
\end{tabular}

* $P$-values calculated by the chi-square test

1.62) than respondents who are married and cohabitate with their spouse.

Figure 1 presents the results for the subgroup analysis of the association between educational level and use of mental health consultation stratified by age. The analysis reveal that, compared to those 70 years or above in age, respondents in the 19 to 29 years old groups in the college or over educational level have a greater odds ratio for mental health consultation. Figure 2 presents the results for the subgroup analysis of the association between educational level and use of mental health consultation stratified according to suicidal thoughts. People who have suicidal thoughts have a stronger association between educational level and use of mental health consultation.

\section{Discussion}

The aim of this study is to identify factors associated with the use of mental health consultation in Korea. The findings reveal that educational level has a positive association with the use of mental health consultation services. Individuals aged 70 years or above tend to undergo mental health consultation less than those aged between 19 and 29 years. Females undergo more mental health consultations than males. Divorced people undergo the most mental health consultation, compared to respondents who are married and cohabitate with their spouse. There is no significant association between household income level and utilization of mental health consultation. Overall, younger people tend to show stronger correlation between educational level and the use of mental health consultation. People who have suicidal thoughts show a stronger association between educational level and use of mental health consultation.

In the present study, we note a significantly positive association between educational levels and the utilization of mental health services. This association may be explained by several reasons. First, highly educated people are more likely to have active attitudes toward mental health services. Individuals who achieve higher educational levels are better at managing their lives, compared to individuals with lower levels of education [31, 32]. The process of studying increases selfconfidence and motivation [31]. These characteristics are essential for successful problem-solving, and highlyeducated people tend to solve their difficulties using an active attitude approach [31-33]. Second, less educated people tend not to recognize their mental health problems [22]. Mental health services are a type of helpseeking process [21]. These help-seeking processes 
Table 2 Factors associated with mental health consultation ${ }^{a}$

\begin{tabular}{ll}
\hline Variables & \multicolumn{2}{l}{ Mental health consultation } \\
\cline { 2 - 3 } & Adjusted OR \\
\hline
\end{tabular}

Educational level - ISCED

$\begin{array}{ll}\text { Low } & 1.00 \\ \text { Medium } & 1.32 \\ \text { High } & 1.35 \\ \text { College or over } & 1.49\end{array}$

Age

$\begin{array}{ll}19-29 & 1.00 \\ 30-39 & 0.89 \\ 40-49 & 0.88 \\ 50-59 & 0.80 \\ 60-69 & 0.86 \\ 70 \leq & 0.46 \\ \text { Gender } & \\ \text { Male } & 1.00 \\ \text { Female } & 1.19\end{array}$

Household income level

Quartile 1 (lowest)

Quartile 2

Quartile 3

1.16

Quartile 4 (highest)

1.17

Region

Capital(Seoul, Gyeonggi)

Urban

1.00

0.98

Rural area

0.99

Marital status

Married-cohabit

Married-no cohabit

1.00

1.29

Bereaved

Divorced

Unmarried

Occupation

High-skilled white collar

Low-skilled white collar

High-skilled blue collar

Low-skilled blue collar

Others

Physical activity

Inactive

Active

Smoking status

Never or former

Current

(0.85-1.14)

(0.88-1.12)
Table 2 Factors associated with mental health consultation ${ }^{a}$ (Continued)

\begin{tabular}{|c|c|c|}
\hline \multirow[t]{2}{*}{ Variables } & \multicolumn{2}{|c|}{ Mental health consultation } \\
\hline & Adjusted OR & $95 \% \mathrm{Cl}$ \\
\hline \multicolumn{3}{|l|}{ Alcohol consumption } \\
\hline Never or former & 1.00 & - \\
\hline Current (within a year) & 0.81 & $(0.71-0.93)$ \\
\hline \multicolumn{3}{|l|}{ Stress level } \\
\hline Very & 1.00 & - \\
\hline Little & 0.65 & $(0.57-0.75)$ \\
\hline No & 0.78 & $(0.58-1.07)$ \\
\hline \multicolumn{3}{|l|}{ Suicidal Thought } \\
\hline Yes & 2.15 & $(1.89-2.43)$ \\
\hline No & 1.00 & - \\
\hline \multicolumn{3}{|l|}{ Sleeping duration } \\
\hline Less than $7 \mathrm{~h}$ & 1.00 & - \\
\hline $7-8 \mathrm{~h}$ & 1.07 & $(0.95-1.20)$ \\
\hline 9 h or over & 1.13 & $(0.91-1.41)$ \\
\hline \multicolumn{3}{|l|}{ Perceived health status } \\
\hline Good & 1.00 & - \\
\hline Normal & 1.31 & $(1.11-1.55)$ \\
\hline Bad & 1.89 & $(1.58-2.26)$ \\
\hline \multicolumn{3}{|c|}{$\begin{array}{l}\text { a Logistic regression analysis was used to determine odds ratios (ORs) and } \\
95 \% \text { confidence intervals (Cls). A total of } 13,269 \text { participants were included in } \\
\text { the analysis. An example of how to interpret this figure is as follows: } \\
\text { 'respondents who received a college or over education are more likely to } \\
\text { receive mental health consultation for depressive symptoms (OR }=1.49 ; 95 \% \\
\text { Cl: } 1.21-1.84 \text { ), compared with respondents with low educational level' }\end{array}$} \\
\hline
\end{tabular}

consist of several steps, including recognizing the problem, realizing the necessary of help, and contacting health services [21]. Because educational level influences awareness of a health care problem, use of mental health services may differ according to the level of education. Third, highly educated people also have more knowledge about mental health services $[34,35]$. They have more opportunities to obtain information about how to manage depression (e.g., receiving a mental health consultation) and access to mental health services $[25,26]$. Finally, education may influence stigma about mental health services. Stigma of what others could think may be a common barrier for contacting mental health services [21]. The stigma associated with mental health consultation influences delays in seeking assistance [36]. Previous studies showed that highly educated people have less stigma about mental health services $[37,38]$. Koreans with mental health problems may have more prejudice against mental health problem than normal people [39]. Also, they tend to avoid making their mental health problems known to other people [39]. Jang et al. identified that such stigma may be influenced by the cultural background in Korea [40]. 


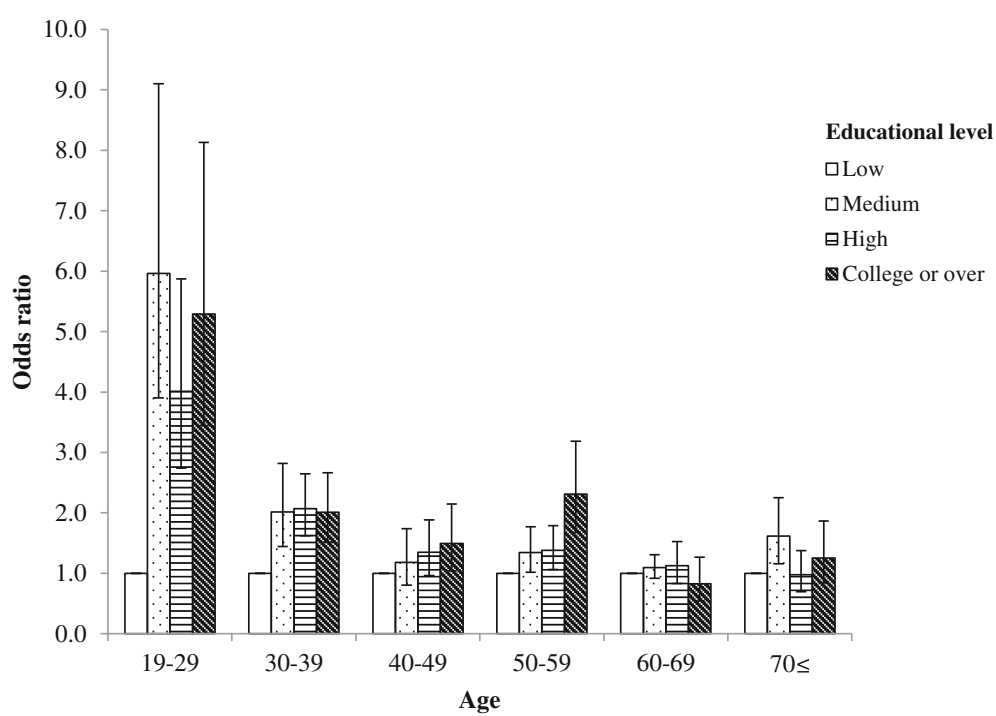

Fig. 1 Subgroup analysis of mental health consultation according to educational level stratified by age. An example of how to interpret this figure is as follows: 'compared with individuals 70 years or above in age, respondents in the 19 to 29 years old groups with college or over educational level have a greater odds ratio for mental health consultation.' Control variables include gender, region, house income level, marital status, occupation, physical activity, smoking status, alcohol consumption, stress level, suicidal thoughts, sleeping duration, and perceived health status

The present study shows that gender and marital status are associated with the utilization of mental health services, while income level has no significantly associations. The results of this study indicated that older adults were less likely to receive mental health consultation. This result was similar to the results of previous studies. Older adults may be less aware of a mental health problem, have a higher sense of self-sufficiency, and be more conscious of the disgrace associated with receipt of mental health services [41, 42]. Females are more likely to use mental health services than males. This correspond with previous studies [22, 43]. Females may be more likely to recognize their emotional problems than men who had similar symptoms [44]. Moreover, females tend to share their emotion with others and be more openness to acknowledging mental health problems [4, 22]. Divorced people are more likely to have mental health services than people who are married

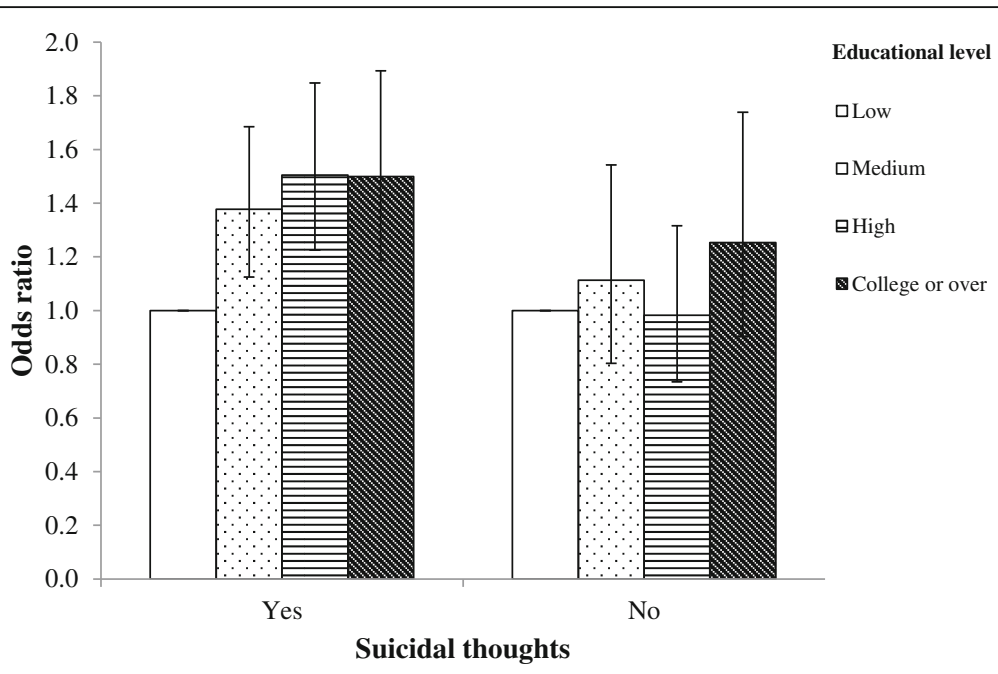

Fig. 2 Subgroup analysis of mental health consultation according to educational level stratified by suicidal thoughts. An example of how to interpret this figure is as follows: 'people who have suicidal thoughts have a stronger association between educational level and use of mental health consultation.' Control variables include age, gender, region, house income level, marital status, occupation, physical activity, smoking status, alcohol consumption, stress level, sleeping duration, and perceived health status 
and cohabit in the study. In many cases, people seek consultation to receive advice for marital problems before divorce [45]. Also, pre-divorce counseling could influence access to mental health consultation. John. T. et al. also identified that separated or divorced people were the most likely to seek mental health services, and our study correspond with previous studies [22].

In the age group of individuals between 19 and 29 years, the association between educational level and use of mental health consultation is stronger than adults 70 years or older. Overall, younger people tend to show stronger correlation between educational level and the use of mental health consultation. This may be related to several factors. Older adults are more prejudiced about the use of mental health consultation and less aware of the severity of their depressive symptoms [41, 42]. Also, the fact that education level influences young people more could be implicated in developing mental health policies.

People who have suicidal thoughts show a stronger association between educational level and use of mental health consultation. People with suicidal thoughts have positive association between educational level and high rates of use of mental health consultation. Therefore, it is necessary to strengthen mental health policies in educational aspects, such as educating people how to manage the depressive symptoms and providing information on mental health services, especially those with suicidal thoughts.

This study has some limitations. First, the data were self-reported by the participants. It is possible that the responses did not correspond to actual consulting rates. Second, we could not examine the type of provider from which the respondents received the consultation, because questions about this factor were not included in the survey. There are also some differences between medical institutions, professional consulting institutions, and local health centres. Third, there was no use of psychometric instruments; the data were only based on participant's subjective view of their depression symptoms. However, the screenings question in the paper were included in the Korean version of the World Health Organization Composite International Diagnostic Interview-Short Form, and validated as a cost-effective screening instrument that could be easily integrated into health surveys [46]. Fourth, people with severe mental illnesses are less likely to respond to a survey. Therefore, it could introduce selection bias in the study population. Finally, the study was based on a cross-sectional survey. Causality could not be confirmed clearly and only association could be confirmed. Despite the above limitations, this study also has several strengths. We used nationally, multistage, stratified collected data that could be considered representative of the Korean population.
Second, although most previous studies were conducted in Caucasians, we conducted research on an Asian society. Third, to the best of our knowledge, this study offers new insights into factors associated with the utilization of mental health services. In particular, Korea ranks highest in suicide rates among OECD countries, and the proportion of suicides due to depression is high. Additionally, the government has proposed policies to address depression rates and to recommend mental health consultation for depressive symptoms in Korea. Therefore, our results seem meaningful.

The most common cause of suicide in Korea is psychiatric problems, and the most typical mental illness people suffer is depression. It has been consistently reported that depression is a serious risk factor of suicide attempts and suicide in previous studies [41, 42]. Moreover, mental health services are considered a significant way of preventing suicide [47]. In this study, we examined factors affecting the use of mental health services to treat depressive symptoms and confirmed that educational level is correlated with the utilization of mental health services. The results could have implications for policies on the use of mental health services in Korea.

\section{Conclusion}

This study identified that only $16 \%$ of individuals with depressive symptoms obtain mental health consultation and that the rates of use of mental health consultation is lower for older adults men, and the divorced. In particular, educational level shows a significant positive association with mental health consultation in the Korea population. This study also presents information about the vulnerable classes of people receiving mental health consultation services. The government should pay more attention to providing public awareness about the symptoms of depression and increase accessibility of mental health consultation services.

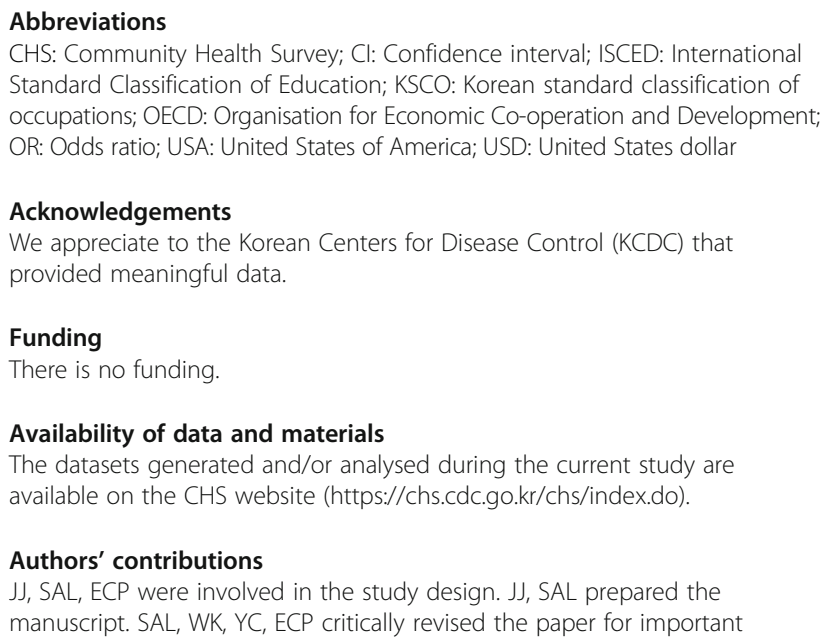


intellectual content. ECP had full access to the article and responsibility for the accuracy of analysis. All authors read and confirm the final version of article to be published. All authors read and approved the final manuscript.

\section{Ethics approval and consent to participate}

Before the beginning of the study, the Community Health Survey received consent from study participants. Instruments and study processes used for the survey were approved by the Korea Centers for Disease Control and Prevention Institutional Review Board (IRB \#: 2013-06EXP-01-3C).

\section{Consent for publication}

Not applicable.

\section{Competing interests}

The authors declare that they have no competing interests.

\section{Publisher's Note}

Springer Nature remains neutral with regard to jurisdictional claims in published maps and institutional affiliations.

\section{Author details}

'Department of Public Health, Graduate School, Yonsei University, Seoul, Republic of Korea. ${ }^{2}$ Institute of Health Services Research, Yonsei University, Seoul, Republic of Korea. ${ }^{3}$ Department of Preventive Medicine \& Institute of Health Services Research, Yonsei University College of Medicine, 50 Yonsei-ro, Seodaemun-gu, Seoul 120-752, Republic of Korea.

Received: 2 March 2017 Accepted: 4 January 2018

Published online: 22 January 2018

\section{References}

1. Wang PS, Aguilar-Gaxiola S, Alonso J, Angermeyer MC, Borges G, Bromet EJ, Bruffaerts R, De Girolamo G, De Graaf R, Gureje O. Use of mental health services for anxiety, mood, and substance disorders in 17 countries in the WHO world mental health surveys. Lancet. 2007;370(9590):841-50.

2. Thornicroft G. Most people with mental illness are not treated. Lancet. 2007; 370(9590):807-8

3. World Health Organization. "Depression: let's talk" says WHO, as depression tops list of causes of ill health. Saudi Med J. 2017;38(5):565.

4. Mackenzie C, Gekoski W, Knox V. Age, gender, and the underutilization of mental health services: the influence of help-seeking attitudes. Aging Ment Health. 2006;10(6):574-82.

5. Segee PF, Maguire L, Ross J, Malik ML, Colket J, Davidson JR. Demographics, treatment seeking, and diagnoses of anxiety support group participants. J Anxiety Disord. 1999:13(3):315-34

6. Rondet C, Parizot I, Cadwallader JS, Lebas J, Chauvin P. Why underserved patients do not consult their general practitioner for depression: results of a qualitative and a quantitative survey at a free outpatient clinic in Paris France. BMC Fam Pract. 2015;16(1):1.

7. Corrigan P. How stigma interferes with mental health care. Am Psychol. 2004;59(7):614.

8. Mathers CD, Loncar D. Projections of global mortality and burden of disease from 2002 to 2030. PLoS Med. 2006;3(11):e442

9. Paykel ES. Depression: major problem for public health. Epidemiol Psychiatr Sci. 2006;15(1):4-10.

10. World Health Organization: The world health report 2001: mental health: new understanding, new hope; 2001.

11. Brent DA. Depression and suicide in children and adolescents. Pediatr Rev. 1993;14(10):380-8.

12. Lesage AD, Boyer R, Grunberg F, Vanier C, Morissette R, Loyer M. Suicide and mental disorders: a case-control study of young men. Am J Psychiatry. 1994;151(7):1063.

13. Cavanagh JT, Carson AJ, Sharpe M, Lawrie SM. Psychological autopsy studies of suicide: a systematic review. Psychol Med. 2003;33(3):395-405.

14. Henriksson MM, Aro HM, Marttunen MJ, Heikkinen ME, Isometsa E, Kuoppasalmi KE, Lonnqvist J. Mental disorders and comorbidity in suicide. Am J Psychiatry. 1993;150:935.

15. Kim C, Lesage A, Seguin M, Chawky N, Vanier C, Lipp O, Turecki G. Patterns of co-morbidity in male suicide completers. Psychol Med. 2003;33(7):1299-309.
16. Dumais A, Lesage A, Alda M, Rouleau G, Dumont M, Chawky N, Roy M, Mann JJ, Benkelfat C, Turecki G. Risk factors for suicide completion in major depression: a case-control study of impulsive and aggressive behaviors in men. Am J Psychiatry. 2005;162(11):2116-24.

17. OECD Publishing: OECD (2016), Society at a Glance 2016: OECD social indicators.

18. Uchida N, CHONG MY, Tan CH, Nagai H, Tanaka M, LEE MS, Fujii S, YANG SY, Si T, Sim K. International study on antidepressant prescription pattern at 20 teaching hospitals and major psychiatric institutions in East Asia: analysis of 1898 cases from China, Japan, Korea Singapore and Taiwan. Psychiatry Clin Neurosci. 2007:61(5):522-8.

19. World Health Organization. Investing in mental health evidence for action: World Health Organization; 2013.

20. Alvidrez J. Ethnic variations in mental health attitudes and service use among low-income African American, Latina, and European American young women. Community Ment Health J. 1999;35(6):515-30.

21. Howard KI, Cornille TA, Lyons JS, Vessey JT, Lueger RJ, Saunders SM. Patterns of mental health service utilization. Arch Gen Psychiatry. 1996;53(8):696-703.

22. Vessey JT, Howard KI. Who seeks psychotherapy? Psychother Theory Res Pract Train. 1993;30(4):546

23. Trude S, Stoddard JJ. Referral gridlock. J Gen Intern Med. 2003;18(6):442-9.

24. Demyttenaere K, Bruffaerts R, Posada-Villa J, Gasquet I, Kovess V, Lepine J, Angermeyer M, Bernert SD, De Girolamo G, Morosini P. Prevalence, severity, and unmet need for treatment of mental disorders in the World Health Organization world mental health surveys. JAMA. 2004;291(21):2581-90.

25. Ross CE, Wu C-L. The links between education and health. Am Sociol Rev. 1995:719-45.

26. Chevalier A, Feinstein L. Sheepskin or Prozac: the causal effect of education on mental health. In: IZA discussion paper no 2231; 2006.

27. Gulliver A, Griffiths KM, Christensen $\mathrm{H}$. Perceived barriers and facilitators to mental health help-seeking in young people: a systematic review. BMC Psychiatry. 2010;10(1):113.

28. Roh S, Lee S-U, Soh M, Ryu V, Kim H, Jang JW, Lim HY, Jeon M, Park J-I, Choi S. Mental health services and R\&D in South Korea. Int J Ment Health Syst. 2016;10(1):45

29. Ministry of Health and Welfare. 2017; Available from: http://www.mohw. go.kr/eng/sg/ssg0101mn.jsp?PAR_MENU_ID=1001\&MENU_ID=100110. Accessed 22 Sept 2017.

30. Smith P, Nüsslin F. Benefits to medical physics from the recent inclusion of medical physicists in the international classification of standard occupation (ICSO-08). Med Phys Int J. 2013;1(1).

31. Mirowsky J, Ross CE. Education, personal control, lifestyle and health a human capital hypothesis. Res Aging. 1998;20(4):415-49.

32. Stansfeld SA, Head J, Marmot M. Explaining social class differences in depression and well-being. Soc Psychiatry Psychiatr Epidemiol. 1997;33(1):1-9.

33. Ross CE, Mirowsky J. Explaining the social patterns of depression: control and problem solving-or support and talking? J Health Soc Behav. 1989:206-19.

34. Ross CE, Wu C-L. Education, age, and the cumulative advantage in health. J Health Soc Behav. 1996;37:104-20.

35. Wood AL, Wahl OF. Evaluating the effectiveness of a consumer-provided mental health recovery education presentation. Psychiatr Rehabil J. 2006:30(1):46.

36. Corrigan PW. Mental health stigma as social attribution: implications for research methods and attitude change. Clin Psychol Sci Pract. 2000;7(1):48-67.

37. Holmes EP, Corrigan PW, Williams P, Canar J, Kubiak MA. Changing attitudes about schizophrenia. Schizophr Bull. 1999;25(3):447.

38. Corrigan PW, Watson AC. The stigma of psychiatric disorders and the gender, ethnicity, and education of the perceiver. Community Ment Health J. 2007:43(5):439-58.

39. Cho SJ, Lee JY, Hong JP, Lee HB, Cho MJ, Hahm BJ. Mental health service use in a nationwide sample of Korean adults. Soc Psychiatry Psychiatr Epidemiol. 2009;44(11):943.

40. Jang Y, Kim G, Hansen L, Chiriboga DA. Attitudes of older Korean Americans toward mental health services. J Am Geriatr Soc. 2007;55(4):616-20.

41. Byers AL, Arean PA, Yaffe K. Low use of mental health services among older Americans with mood and anxiety disorders. Psychiatr Serv. 2012;63(1):66-72.

42. Dalrymple KL, Zimmerman M. Treatment-seeking for social anxiety disorder in a general outpatient psychiatry setting. Psychiatry Res. 2011;187(3):375-81.

43. Regier DA, Narrow WE, Rae DS, Manderscheid RW, Locke BZ, Goodwin FK. The de facto US mental and addictive disorders service system: epidemiologic catchment area prospective 1-year prevalence rates of disorders and services. Arch Gen Psychiatry. 1993;50(2):85-94. 
44. Wang PS, Lane M, Olfson M, Pincus HA, Wells KB, Kessler RC. Twelve-month use of mental health services in the United States: results from the National Comorbidity Survey Replication. Arch Gen Psychiatry. 2005;62(6):629-40.

45. Amato PR. The consequences of divorce for adults and children. J Marriage Fam. 2000;62(4):1269-87.

46. Gigantesco A, Morosini P. Development, reliability and factor analysis of a self-administered questionnaire which originates from the World Health Organization's composite international diagnostic interview-short form (CIDI-SF) for assessing mental disorders. Clin Pract Epidemiol Ment Health. 2008;4(1):8.

47. US Public Health Service. The surgeon General's call to action to prevent suicide. Washington, DC: author; 1999.

Submit your next manuscript to BioMed Central and we will help you at every step:

- We accept pre-submission inquiries

- Our selector tool helps you to find the most relevant journal

- We provide round the clock customer support

- Convenient online submission

- Thorough peer review

- Inclusion in PubMed and all major indexing services

- Maximum visibility for your research

Submit your manuscript at www.biomedcentral.com/submit
Biomed Central 